\title{
Conditions of oral health in elderly of rural areas
}

\begin{abstract}
The increase in life expectancy worldwide has not necessarily been accompanied by better living conditions and particularly oral health. The elderly living in rural areas are considered to have low access to dental care being those greatly affected by oral diseases. The aim of this study was to know the oral conditions of 76 elderly people living in a rural area. The population examined showed low schooling, 36.8\% did not report any year of formal education and $31.5 \%$ had less than four years of formal schooling, with the majority being married (59.2\%). After applying the WHO principles by a previously trained examiner, the results showed that the tongue coating was the most prevalent mucosa alteration $(67.7 \%)$, the prevalence of dental loss was high, with only 6.6 teeth present by the elderly and $54 \%$ of total edentulous patient. The mean DMFT was 28.1, one root caries was found by the elderly among the elderly who had teeth; $50 \%$ of the elderly presented periodontal pockets and $83.3 \%$ loss of periodontal insertion above $3 \mathrm{~mm}$. About $50 \%$ of the elderly did not use prostheses in the maxilla, and $69.2 \%$ did not use in the lower jaw; regarding the need for prostheses in the upper and lower jaw only $26.9 \%$ and $23.1 \%$ did not need prostheses, respectively. The population studied was highly vulnerable with alarming oral conditions, needing to be a priority in specific government programs.
\end{abstract}

Keywords: aged, rural areas, oral health, periodontal diseases, dental caries, prostheses and implants
Volume 4 Issue 2 - 2019

\author{
Montandon AAB,' Pinelli LAP, ${ }^{2}$ Ricci WA,' \\ Piveta ACRG,' Muñoz-Cháves OF,' Barros \\ LAB,' Nagle MM' \\ 'Department of Social Dentistry, Araraquara School of \\ Dentistry, UNESP-São Paulo State University, Brazil \\ ${ }^{2}$ Department of Dental Materials and Prosthodontics, \\ Araraquara School of Dentistry, UNESP- São Paulo State \\ University, Brazil
}

Correspondence: Andréia Affonso Barretto Montandon, Department of Social Dentistry, Araraquara School of Dentistry, UNESP- São Paulo State University, Rua Humaitá, 1680 CEP | 480 |-903, Araraquara, SP, Brazil, Tel +5516330|6350,

Email andreia.montandon@unesp.br

Received: February 25, 2019 | Published: April 04, 2019

\section{Introduction}

The elderly population in Brazil is among the fastest growing in the world. Massive urbanization and declining rates of mortality and fertility contribute to the future realization of the estimate that Brazil should have the sixth largest population of the elderly, representing more than 32 million individuals aged 60 or over, about $15 \%$ its total population. ${ }^{1}$

Health is the ability of the individual, independent of his or her age to continue to function in their physical and social environment, contributing to and interacting with society ${ }^{2}$ and oral health is an essential component of the general health and well-being of the individual influencing the productivity and quality of life and most of the times is not of its importance recognized, mainly by elderly people, where the loss of teeth is accepted as a natural phenomenon that accompanies aging. ${ }^{3}$ However, it is known that diseases developed in the oral cavity, such as caries or periodontal diseases, may be frequently associated with some systemic diseases such as arteriosclerosis, diabetes and heart diseases. ${ }^{4}$

In Brazil, oral health indicators for the elderly population living in rural areas are critical..$^{5-7}$ Knowledge of the needs related to this population is important to support the planning of oral health care for the elderly. ${ }^{8}$ Oral health care and periodic returns to the dental office help to maintain the general health of the patient, as oral diseases belong to a group of diseases that can be avoided with preventive measures (Martins et al.)

Shah and Sundaram ${ }^{9}$ evaluated 524 elderly residents in rural areas regarding the impact of socio-demographic variables, oral hygiene practices and habits on the periodontal conditions measured by the CPI (Community Periodontal Index), presence of gingival recession, dental mobility and halitosis. The authors found a high prevalence of periodontal diseases, with a positive association with age, oral hygiene practices and presence of heart disease. More recently, some authors, ${ }^{10-12}$ have also found more alarming oral conditions in elderly rural dwellers with high rates of tooth loss, root caries, periodontal disease as well as greater masticatory difficulties. Such elderly people were usually low-income and poorly educated.

The damage caused by lack of oral health care increases with age, resulting in tooth loss and increased need for prosthetic use. In addition to this, public health systems have long been curative and mutilating, ${ }^{13}$ especially in relation to the population living in rural areas, which is a condemned practice in the present day.

Martins et al. ${ }^{6}$ investigated the use of dental services among dentate and edentulous elderly residents in the southeastern region of Brazil, comparing the elderly who used the service for less than a year with those who used it for more than a year. Older people who perceived that speech was influenced by the condition of oral health were the ones that used the service the most, while the elderly living in rural areas and with lower income were the ones that used the service the least. In the edentulous ones, the greater use was among elderly with painful sensitivity in the oral cavity. Saliba et al. ${ }^{7}$ verified the dental loss in a rural population and evaluated the contribution of socioeconomic and behavioral variables; dental loss advanced considerably with age, and the situation was far below the goals established by the WHO for 2010 .

The scarcity of epidemiological studies in the rural population may compromise information on oral health. For these, access to public services in general, schools, hospitals and health facilities can be difficult due to the distance of properties and precarious transport services. ${ }^{7,14}$ These and other factors, such as the absence of water treatment systems, ${ }^{6,15}$ sewage and garbage collection may also compromise the health of this population.

A British study involving 876 elderly people over 65 years old was conducted to identify the relationship between social support, oral health status and behavior in relation to the maintenance of this. This study found a close relationship between them that influences the decision making between the demand for dental care and the type of treatment performed. ${ }^{16}$ 
Thus, the numerous factors that influence oral health in elderly patients, an integral part of their health, lead to a better understanding of their behavior in specific communities so that community programs ${ }^{17-19}$ can more specifically achieve their goals, considering that aging with independence must be sought by all health professionals in a philosophy of multidisciplinary care. An analysis of these aspects may lead to a better understanding of the variability of the dental condition and thus increase our knowledge about factors that promote oral health even in old age. Therefore, the objective of this study was to know the behavior of oral and social health indicators of elderly residents in the rural area of Araraquara, State of São Paulo, Brazil.

\section{Methods}

This study is a transversal type epidemiological survey, applied to 94 elderly residents of the Bela Vista settlement, Araraquara, São Paulo, Brazil. Inclusion criteria were age (over 60 years) and nonrejection of clinical examination; the exclusion criteria were related to factors that determine the risk of bacterial endocarditis in totally or partially dentate patients due to periodontal probing procedures following the American Heart Association guidelines. ${ }^{20}$ Medical information was confirmed in the patient's medical record.

The present study was submitted to the Research Ethics Committee of the School of Dentistry of Araraquara (Protocol 49/05) and the elderly signed a consent form authorizing the interview and examinations. Socio-demographic variables were collected such as age in full years, marital status, years of schooling, and family income in minimum salaries.

The clinical examination followed the methodology recommended by the $\mathrm{WHO}^{21}$ and was performed by a single examiner previously trained using sterilized kits containing wooden spatulas and gauze, a periodontal probe specially recommended by WHO (Trinity®), as well as clinical mirror and Individual Protection Equipment (IPE). In the extra-oral examination, it was verified the presence and location of lesions and tissue alterations, as well as the presence or absence of xerostomia. The periodontal conditions measured by the CPI (Community Periodontal Index) were verified for the presence of periodontal pockets and PI (Periodontal Index) to determine the level of periodontal insertion, besides the use and needs of prostheses.

The presence of prostheses was recorded for both the maxilla and the mandible, considering the absence of prosthesis (score 0 ), fixed partial prosthesis (score 1), more than one fixed partial denture (score 2), partial removable prosthesis (score 3 ), presence of both partial and removable partial prostheses (score 4) or complete dentures (score 5). The prosthetic need was also recorded for the maxilla and mandible, according to the following criteria: there is no need for prosthesis (score 0 ), need for a unitary prosthesis (score 1), need for a prosthesis with multiple elements (score 2), need for unitary prosthesis and/or with multiple elements (score 3) and need for a complete denture (score 4). After the data collection, a database was created, and the descriptive analysis of the collected variables, made through the preparation of tables.

\section{Results}

Of the ninety-four-elderly living in the rural area selected for the study, only 76 elderly $(80.9 \%$ of the elderly population living in the settlement) adequately completed all the steps to be included in the data. The age varied between 60 and 91 years (mean 74.3 years-old), $56.6 \%$ of males and $43.4 \%$ of females. The majority was marriage (59.2\%), 36.8\% with no schooling and $31.5 \%$ had less than four years of formal schooling; $40.8 \%$ of the elderly received one minimum salary (approximately U\$280.00) or less.
Forty-six percent of the sample was partially dentate and $54 \%$ edentulous. Figure 1 and Tables 1-9 show the results analyzed. Of the 76 patients examined, $31(40.79 \%)$ had mucosa alterations according to the Figure 1.

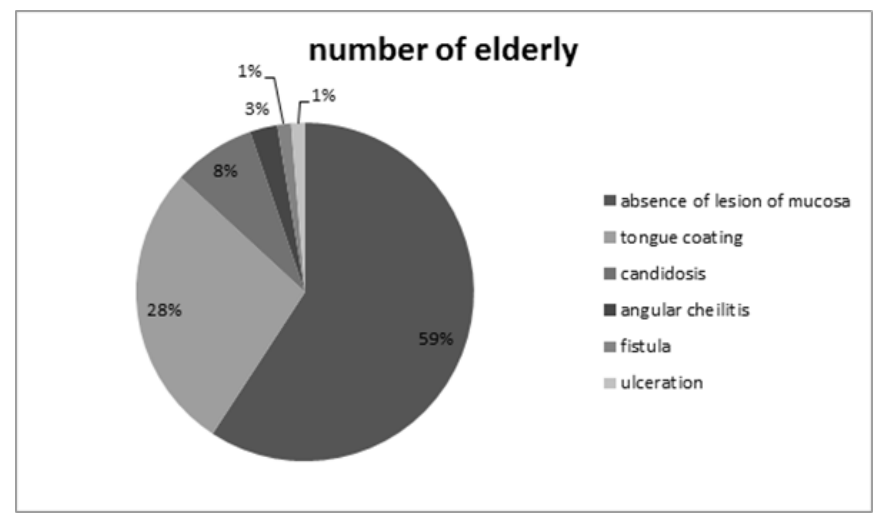

Figure I Prevalence of mucosal alterations in the patients examined $(n=76)$. Table I Mean values for number of teeth present, DMFT, and root caries in the population studied by age group $(n=36)$

\begin{tabular}{|c|c|c|c|c|c|c|}
\hline \multirow{2}{*}{$\begin{array}{l}\text { Age } \\
\text { group }\end{array}$} & \multirow{2}{*}{$\begin{array}{l}\text { Mean } \\
\text { number of } \\
\text { teeth present }\end{array}$} & \multicolumn{4}{|l|}{ DMFT } & \multirow{2}{*}{$\begin{array}{l}\text { Average } \\
\text { number of } \\
\text { root caries }\end{array}$} \\
\hline & & Mean & D & $\mathbf{M}$ & $\mathbf{F}$ & \\
\hline 55 |---| 64 & 2.3 & 30.4 & 0.3 & 29.7 & 0.4 & 0.0 \\
\hline 74 |---| 65 & 9.2 & 27.2 & 2.0 & 22.8 & 2.4 & I.I \\
\hline 84 & 7.0 & 26.6 & 1.0 & 25.0 & 0.6 & 3.0 \\
\hline 94 |---| 85 & 0.0 & 32.0 & 0.0 & 32.0 & 0.0 & 0.0 \\
\hline | 60 |--- & 6.6 & 28.1 & 1.3 & 25.4 & 1.4 & I.I \\
\hline
\end{tabular}

Table 2 Frequency (\%) of dentate patients according to the highest score for the community periodontal index $(\mathrm{CPI})$ and age group $(n=36)$

\begin{tabular}{|c|c|c|c|c|c|c|}
\hline \multirow{2}{*}{ Age group } & \multirow{2}{*}{$\begin{array}{l}\text { Number of elderly } \\
\text { partially dentate }\end{array}$} & \multicolumn{5}{|c|}{ Highest score for CPI } \\
\hline & & 0 & I & 2 & 3 & 4 \\
\hline 55 |---| 64 & 3 & - & - & 100,0 & - & - \\
\hline 74 |---| 65 & 27 & - & $\mathrm{II}, \mathrm{I}$ & 22,2 & 55,5 & $\mathrm{II}, \mathrm{I}$ \\
\hline 75 |---| 84 & 6 & - & - & 50,0 & 50,0 & - \\
\hline 60 |---| 84 & 36 & - & 8,3 & $4 I, 7$ & 33,3 & 16,7 \\
\hline
\end{tabular}

0 , healthy tooth; I, bleeding; 2, calculus and/or marginal excess of restoration; 3 , periodontal pocket of $4-5 \mathrm{~mm}$ (black band of the probe partially visible), 4 , periodontal pocket of $6 \mathrm{~mm}$ or more (black band of probe not visible)

Table 3 Mean number of sextants according to the highest score of the community periodontal index $(\mathrm{CPI})$ and age group in dentate elderly $(n=36)$

\begin{tabular}{|c|c|c|c|c|c|c|c|}
\hline \multirow{2}{*}{ Age group } & \multirow{2}{*}{$\begin{array}{l}\text { Number of elderly } \\
\text { partially dentate }\end{array}$} & \multicolumn{6}{|c|}{ Sextants with score CPI } \\
\hline & & 0 & I & 2 & 3 & 4 & Absent \\
\hline $55|---| 64$ & 3 & $\mathrm{I}, 0$ & $\mathrm{I}, 0$ & 2,0 & - & - & 2,0 \\
\hline $65|---| 74$ & 27 & 0,1 & 0,4 & 2,1 & 0,7 & 0,1 & 2,7 \\
\hline 75 |---| 84 & 6 & - & $\mathrm{I}, 0$ & 2,0 & $\mathrm{I}, 0$ & 0,5 & 1,5 \\
\hline 64 |---| 84 & 36 & 0,2 & 0,6 & 2,1 & 0,7 & $\mathrm{I}, 2$ & 2,4 \\
\hline
\end{tabular}

0 , healthy tooth; I, bleeding; 2 , calculus and/or marginal excess of restoration; 3 , periodontal pocket of $4-5 \mathrm{~mm}$ (black band of the probe partially visible), 4 , periodontal pocket of $6 \mathrm{~mm}$ or more (black band of probe not visible) 
Table 4 Frequency (\%) of dentate patients according to highest score of Periodontal Insertion Index (PI) and age group $(n=36)$

\begin{tabular}{|c|c|c|c|c|c|c|}
\hline \multirow{2}{*}{ Age Group } & \multirow{2}{*}{$\begin{array}{l}\text { Number of elderly } \\
\text { partially dentate }\end{array}$} & \multicolumn{5}{|c|}{ Highest score PI } \\
\hline & & 0 & I & 2 & 3 & 4 \\
\hline $55|---| 64$ & 3 & - & - & - & 100,0 & - \\
\hline $65|---| 74$ & 27 & 22,2 & 55,6 & $\mathrm{II}, \mathrm{I}$ & 11,1 & - \\
\hline 75 |---| 84 & 6 & - & - & 100,0 & - & - \\
\hline $60|---| 84$ & 36 & 16,7 & 41,6 & 25,0 & 16,7 & - \\
\hline
\end{tabular}

$0=0-3 \mathrm{~mm} ; \mathrm{I}=4-5 \mathrm{~mm}$ (cementitious junction within the black band of the probe); $2=6-8 \mathrm{~mm}$ (cementitious junction between the upper limit of the black band and the $8.5 \mathrm{~mm}$ ring); $3=9-1 \mathrm{Imm}$ (cementitious junction between the rings of $8.5 \mathrm{~mm}$ and $11 \mathrm{~mm}$ ); $4=12 \mathrm{~mm}$ or more (cementitious junction in addition to the $11.5 \mathrm{~mm}$ ring)

Table 5 Mean number of sextants according to highest score of periodontal insertion index $(\mathrm{PI})$ and age group in dentate elderly $(\mathrm{n}=36)$

\begin{tabular}{|c|c|c|c|c|c|c|c|}
\hline \multirow{2}{*}{ Age group } & \multirow{2}{*}{$\begin{array}{l}\text { Number of elderly } \\
\text { partially dentate }\end{array}$} & \multicolumn{6}{|c|}{ Average number of sextants - $\mathrm{PI}$} \\
\hline & & 0 & $\mathbf{I}$ & 2 & 3 & 4 & Absent \\
\hline $55|---| 64$ & 3 & - & 3,0 & - & $\mathrm{I}, 0$ & - & 2,0 \\
\hline $65|---| 74$ & 27 & $\mathrm{I}, 4$ & $\mathrm{I}, 4$ & 0,2 & 0,2 & - & 2,7 \\
\hline $75|---| 84$ & 6 & 2,5 & 1,0 & $\mathrm{I}, 0$ & - & - & $\mathrm{I}, 5$ \\
\hline $60|---| 84$ & 36 & I,5 & 1,5 & 0,3 & 0,3 & - & 2,4 \\
\hline
\end{tabular}

$0=0-3 \mathrm{~mm} ; \mathrm{I}=4-5 \mathrm{~mm}$ (cementitious junction within the black band of the probe); $2=6-8 \mathrm{~mm}$ (cementitious junction between the upper limit of the black band and the $8.5 \mathrm{~mm}$ ring); $3=9-1 \mathrm{Imm}$ (cementitious junction between the rings of $8.5 \mathrm{~mm}$ and $1 \mathrm{Imm}$ ); $4=12 \mathrm{~mm}$ or more (cementitious junction in addition to the $11.5 \mathrm{~mm}$ ring)

Table 6 Frequency (\%) of patients studied according to the prosthetic condition in the upper jaw and age group $(n=76)$

\begin{tabular}{lllllllll}
\hline \multirow{2}{*}{ Age Group } & \multicolumn{6}{c}{ Maxillary prosthetic condition } \\
\cline { 2 - 7 } & $\mathbf{0}$ & $\mathbf{2}$ & $\mathbf{2}$ & $\mathbf{4}$ & $\mathbf{5}$ & Total \\
\hline $55|--|$ & 64 & 57,1 & - & - & - & - & 42,9 & 100,0 \\
$65|--|$ & 74 & 38,5 & - & - & $\mid 5,4$ & - & $46, \mid$ & 100,0 \\
$75|--|$ & 84 & 60,0 & - & - & - & - & 13,3 & 100,0 \\
$85|--|$ & 94 & 100,0 & - & - & - & - & - & 100,0 \\
\hline $60|--|$ & 91 & 50,0 & - & - & 7,7 & - & 42,3 & 100,0 \\
\hline
\end{tabular}

$0=$ no prosthesis; I=fixed partial prosthesis; 2 , more than one fixed partial prosthesis; 3, removable partial prosthesis; 4=partial prosthesis-fixed and removable; $5=$ complete dentures

Table 7 Percentage of patients studied according to the prosthetic condition in the lower jaw and age group $(n=76)$

\begin{tabular}{|c|c|c|c|c|c|c|c|}
\hline \multirow{2}{*}{ Age Group } & \multicolumn{7}{|c|}{ Mandibular prosthetic condition } \\
\hline & 0 & $\mathbf{I}$ & 2 & 3 & 4 & 5 & Total \\
\hline $55|---| 64$ & 57,1 & - & - & - & - & 42,9 & 100,0 \\
\hline $65|---| 74$ & 69,2 & - & - & 15,4 & - & 15,4 & 100,0 \\
\hline $75|---| 84$ & 80,0 & - & - & - & - & 20,0 & 100,0 \\
\hline 85 |---| 94 & 100,0 & - & - & - & - & - & 100,0 \\
\hline $60 \mid---91$ & 69,2 & - & - & 7,6 & - & 19,2 & 100,0 \\
\hline
\end{tabular}

0 , no prosthesis; I, fixed partial prosthesis; 2 , more than one fixed partial prosthesis; 3, removable partial prosthesis; 4, partial prosthesis - fixed and removable; 5 , complete dentures
Table 8 Percentage of patients studied according to prosthetic need in the upper jaw and age group $(n=76)$

\begin{tabular}{|c|c|c|c|c|c|c|}
\hline \multirow{2}{*}{ Age Group } & \multicolumn{6}{|c|}{ Prosthetic need in the upper jaw } \\
\hline & 0 & $\mathbf{I}$ & 2 & 3 & 4 & Total \\
\hline 55 |---| 64 & 28,6 & - & 14,3 & - & 57,1 & 100,0 \\
\hline 65 |---| 74 & 38,5 & - & 15,3 & 7,7 & 38,5 & 100,0 \\
\hline 75 |---| 84 & - & - & 20,0 & - & 80,0 & 100,0 \\
\hline $85|---| 94$ & - & - & - & - & 100,0 & 100,0 \\
\hline $60|---| 9 \mid$ & 26,9 & - & 15,4 & 3,8 & 53,9 & 100,0 \\
\hline
\end{tabular}

0 , no prosthesis, I, fixed partial prosthesis; 2 , more than one fixed partial prosthesis; 3, removable partial prosthesis; 4, partial prosthesis - fixed and removable; 5 , complete dentures

Table 9 Percentage of patients studied according to prosthetic need in the lower jaw and age group $(n=76)$

\begin{tabular}{|c|c|c|c|c|c|c|}
\hline \multirow{2}{*}{ Age Group } & \multicolumn{6}{|c|}{ Prosthetic need in the lower jaw } \\
\hline & 0 & I & 2 & 3 & 4 & Total \\
\hline $55|---| 64$ & 14,3 & - & 14,3 & - & $7 I, 4$ & 100,0 \\
\hline $65|---| 74$ & 38,4 & - & 23,1 & 23,1 & 15,4 & 100,0 \\
\hline $75|---| 84$ & - & - & 20,0 & - & 80,0 & 100,0 \\
\hline $85|---| 94$ & - & - & - & - & 100,0 & 100,0 \\
\hline $60|--| 9 \mid$ & 23,1 & - & 19,2 & 11,5 & 46,2 & 100,0 \\
\hline
\end{tabular}

0 , No prosthesis; I, fixed partial prosthesis; 2, more than one fixed partial prosthesis; 3, removable partial prosthesis; 4, partial prosthesis -fixed and removable; 5 , complete dentures

Tables 1 to 5 refer to data collected exclusively on 36 partially dentate elderly $(47.37 \%)$, while the tables 6 to 9 refer to the total population examined $(n=76)$.

\section{Discussion}

The data collection of this study had as objective to know the oral health of elderly residents in the rural area, which according to WHO (1991). The concept of active aging requires the active participation of the elderly in the society in which they live and not necessarily the absence of diseases ${ }^{2}$ and the multidisciplinary view of the elderly care approach requires their knowledge as a whole.

In the United States, some authors ${ }^{14,17}$ also relate contextual factors such as distance and transportation difficulty as the main determinants that affect the oral health of residents in rural American areas. In addition, residents of rural areas have a socioeconomic situation that makes it difficult for periodic visits to dental offices. ${ }^{6}$ This condition was evidenced in relation to the verified numbers of income and schooling, considering that $36.8 \%$ of the elderly presented in schooling and $31.5 \%$ had less than four years of formal schooling; $40.8 \%$ of the elderly received one minimum salary (approximately $\$ 280.00$ ). In a study by Kim et al. ${ }^{12}$ the poor social network was associated with poor chewing ability in the elderly living in rural areas.

The oral health analysis of the elderly showed that the most prevalent mucosa alteration was tongue coating $(67.7 \%)$, followed by the high prevalence of dental loss, with 6.6 teeth present on average by the elderly and $54 \%$ of total edentulous. These numbers were shown to be much more expressive in comparison to those data of dental loss in the elderly living in rural area obtained by Caldwell et al. ${ }^{10}$ and Masood et al. ${ }^{11}$ The mean DMFT was 28.1 , with the elderly 
having one root carie on average. Among the elderly who had teeth, $50 \%$ had periodontal pockets and $83.3 \%$ lost periodontal insertion over 3 millimeters.

From the epidemiological point of view, caries is possibly the most important multifactorial oral disease, and its close association with diet and lifestyle also gives it anthropological relevance. ${ }^{13,18,22}$ In the studied rural population, it can be observed that the diet allied to the practice of oral hygiene insufficient and difficulty of access to the dental offices lead to the existing epidemiological picture. As the age increased, the number of people with decayed teeth decreased and caries-free teeth increased, indicating an increase in tooth loss with age followed by the need for treatment with dentures. The prevalence of caries disease shows a decline with increasing age and according to Shah and Sundaram ${ }^{9}$ its risk is directly related to dental loss, oral hygiene habits, diet and considering old age of the study population, social support. ${ }^{16}$

Dentist appointments, unlike the visits to the doctor, seem to reduce with aging, ${ }^{6}$ and a low rate of use of dental services among the elderly is expected. This condition can be evidenced by the high prevalence of natural tooth loss among Brazilian elderly. ${ }^{3}$ The scarcity of studies directed to the elderly rural population in Brazil makes it difficult to compare the subject, ${ }^{7}$ and the majority of the studies are directed to urban residents or school children.

In the age group of 55-64 years-old, the prevalence of edentulous was higher than that found by other authors. ${ }^{4,6,7,19}$ The elderly population is growing and needs specific oral health policies to reduce edentulism, improve general health conditions and quality of life. It is important to motivate dentate and edentulous elderly about the importance of using dental services, since it is perceived that the demand exists, especially in the population that lives in rural areas only when the oral health situation is critical, in the face of incurable pain or lesions with home therapy. ${ }^{6}$

In this study, about $50 \%$ of the elderly did not use prosthesis in the upper jaw and $69.2 \%$ in the lower jaw. Regarding the need for prostheses in the upper and lower jaw, only $26.9 \%$ and $23.1 \%$ did not require prostheses, respectively (Tables 18 to 21 ), indicating the existence of a high demand for prosthetic services. Since edentulism is a prevalent condition in Brazil and irreversible among those affected, it is important to know the factors associated with the use of dental services in this specific population, in order to contribute to targeted oral health policies that can improve the quality of life of this population. ${ }^{6}$

Conditions that affect access to dental care are multifactorial and include social, economic and cultural factors. ${ }^{16}$ According to some studies ${ }^{6,4,8,15,17,19}$ residents of rural areas are usually affected by these conditions due to the difficulty of transportation and access to dental offices and do not have the financial resources for this type of treatment. The distance to be covered by rural dwellers varies depending on the region, but in general, they are significant barriers for the elderly, low income, self-employed and limited public transportation. It is necessary to develop oral health care programs in order to reduce the damage caused and to prevent the continuation of the tendency towards mutilation, especially in the elderly population.?

The oral health conditions found in the studied population should be considered in the provision of dental care, with a multidisciplinary approach. The limitation of this research was the sample size, which although it corresponded to approximately $80 \%$ of the elderly residents of the studied region still reflects specific data of the target population, that is, although small number of elderly is representative of the oral conditions faced by the elderly of rural area. Such a study shows the need for broader interventions in rural areas.

\section{Conclusion}

The elderly patients examined presented precarious oral health conditions, with high prevalence of mucosal lesions, few teeth present and high need of prostheses, which shows that this population was highly vulnerable with alarming oral conditions, needing to be a priority in specific government programs.

\section{Acknowledgments}

None.

\section{Conflicts of interest}

Authors declare that there is no conflicts of interest

\section{References}

1. Ramos LR, Toniolo J, Cendoroglo MS, et al. Two-year follow-up study of elderly residents in S. Paulo, Brazil: methodology and preliminary results. Rev Saude Publica. 1998;32(5):397-407.

2. Paschoal SMP. Autonomia e independência. In: Papaléo Netto M. Gerontologia: a velhice em visão globalizada. São Paulo: Atheneu; 2002.

3. Matos DL, Giatti L, Lima CMF. Socio-demographic factors associated with dental services among Brazilian older adults: a study based on the national household sample survey. Cad Saude Publica. 2004;20(5):12901297.

4. Davis MM, Hilton TJ, Benson S, et al. Unmet dental needs in rural primary care: a clinic-, community-, and practice-based research network collaborative. J Am Board Fam Med. 2010;23(4):514-22.

5. Newman JF, Gift HC. Regular pattern of preventive dental services--a measure of access. Soc Sci Med. 1992;35(8):997-1001.

6. Martins AM, Barreto SM, Pordeus IA. Characteristics associated with use of dental services by dentate and edentulous elders: the SB Brazil project. Cad Saude Publica. 2008;24(1):81-92.

7. Saliba NA, Moimaz SAS, Saliba O, et al. Perda dentária em uma população rural e as metas estabelecidas pela organização mundial de saúde. Ciência \& Saúde Coletiva. 2010;15(Supl 1):1857-1864.

8. Matos DL, Lima CMF. Trends in the use of dental services by elderly Brazilians and related socio-demographic factors based on the National Household Survey (1998 and 2003). Cad Saude Publica. 2007;23(11):2740-2748.

9. Shah N, Sundaram KR. Impact of socio-demographic variables, oral hygiene practices, oral habits and diet on dental caries experience of Indian elderly: a community-based study. Gerodontology. 2004;21(1):43-50.

10. Caldwell JT, Lee H, Cagney KA. The role of primary care for the oral health of rural and urban older adults. J Rural Health. 2017;33(4):409418 .

11. Masood M, Newton T, Bakri NN, et al. The relationship between oral health and oral health related quality of life among elderly people in United Kingdom. J Dent. 2017;56:78-83.

12. Kim EK, Jung YS, Kim KH, et al. Social capital and oral health: The association of social capital with edentulism and chewing ability in the rural elderly. Arch Gerontol Geriatr. 2018;74:100-105.

13. Silva RH, Castro RF, Cunha DC, et al. Dental caries in a riverine community in rondônia state, amazon Region, Brazil, 2005-2006. Cad Saude Publica. 2008;24(10):2347-2353. 
14. Skillman SM, Doescher MP, Mouradian WE, et al. The challenge to delivering oral health services in rural America. J Public Health Dent. 2010;70(1):S49-57.

15. Fischer TK, Peres KG, Kupek E, et al. Primary dental care indicators association with socioeconomic status, dental care, water fluoridation and Family Health Program in Southern Brazil. Rev Bras Epidemiol. 2010;13(1):126-138.

16. McGrath C, Bedi R. Influences of social support on the oral health of older people in Britain. J Oral Rehabil. 2002;29(10):918-922.

17. Ahn S, Burdine JN, Smith ML, et al. Residential rurality and oral health disparities: influences of contextual and individual factors. J Prim Prev. 2011;32(1):29-41.

18. Arantes R, Santos RV, Coimbra CE . Oral health among the Xavánte Indians in Pimentel Barbosa, Mato Grosso, Brazil. Cad Saude Publica. 2001;17(2):375-384.
19. Bastos RS, Silva RP, Maia JAF, et al. Dental caries profile in monte negro, Amazonian state of Rondônia, Brazil, in 2008. J Appl Oral Sci. 2010;18(5):437-441

20. Wilson W, Taubert KA, Gewitz M, et al. Prevention of infective endocarditis: guidelines from the American Heart Association: a guideline from the american heart association rheumatic fever, endocarditis, and kawasaki disease committee, council on cardiovascular disease in the young, and the council on clinical cardiology, council on cardiovascular surgery and anesthesia, and the quality of care and outcomes research interdisciplinary working group. Circulation. 2007 Oct 9;116(15):17361754 .

21. Organização Mundial da Saúde. Levantamento epidemiológico básico de saúde bucal: manual de instruções. 3rd edition. São Paulo: Editora Santos; 1991.

22. Narvai PC, Frazão P, Roncalli AG, et al. Cárie dentária no Brasil: declínio, polarização, iniqüidade e exclusão social. Rev Panam Salud Pública. 2006;19:385-389. 